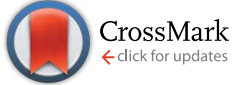

Cite this: RSC Adv., 2014, 4, 51256
Received 22nd August 2014

Accepted 22nd September 2014

DOI: $10.1039 / \mathrm{c} 4 \mathrm{ra0} 0116 \mathrm{~g}$

www.rsc.org/advances

\section{Enhanced carrier transport in tris(8- hydroxyquinolinate) aluminum by titanyl phthalocyanine doping}

\begin{abstract}
M. Ramar, Priyanka Tyagi, C. K. Suman* and Ritu Srivastava
The effect of doping titanyl phthalocyanine (TiOPC) into tris(8-hydroxyquinolinate) aluminum ( $\left.\mathrm{Alq}_{3}\right)\left(\mathrm{Alq}_{3}: \mathrm{T}\right.$; where $T$ represents TiOPc), used as an electron transport layer (ETL) for organic light emitting diodes (OLEDs), was investigated. The surface roughness of the doped thin films increases with the doping concentration as a result of a needle like 3D growth of TiOPc in $\mathrm{Alq}_{3}$. The electron mobility depends on the doping concentration. The electron mobility calculated in the trap-free space-charge limited region (SCLC) for a $2 \%$ doped $\mathrm{Alq}_{3}$ thin film was found to be $0.17 \times 10^{-5} \mathrm{~cm}^{2} \mathrm{~V}^{-1} \mathrm{~s}^{-1}$ which is four orders of magnitude greater than that for pristine $\mathrm{Alq}_{3}$. The electroluminescence at a constant current density of $10 \mathrm{~mA} \mathrm{~cm}{ }^{-2}$ is $3098,4700,7800,3600$ and $520 \mathrm{~cd} \mathrm{~m}^{-2}$ for $\mathrm{Alq}_{3}$ to $\mathrm{Alq}_{3}: \mathrm{T}(1 \%, 2 \%, 3 \%$ and $5 \%$ ) devices, respectively. Similarly the power efficiency at a constant current density of $10 \mathrm{~mA} \mathrm{~cm}{ }^{-2}$ is $2.1,2.7,4.2$, 1.3 and $0.48 \mathrm{Im} \mathrm{W}^{-1}$ for the different doped devices $\mathrm{Alq}_{3}$ to $\mathrm{Alq}_{3}: \mathrm{T}(1 \%, 2 \%, 3 \%$ and $5 \%$, respectively. The OLEDs based on the optimized $2 \%$ doped TiOPC in $\mathrm{Alq}_{3}$ show a four times increase in the electroluminescence as well as an almost doubling of the power efficiency. There are interfacial charges near the doped layer. The Cole-Cole plot indicates the device can be modeled as the combination of three parallel resistance-capacitance $(R-C)$ equivalent circuits.
\end{abstract}

\section{Introduction}

Since the first successful demonstration of organic light emitting diodes (OLEDs) by Tang and Van Slyke, ${ }^{\mathbf{1 , 2}}$ good steady progress has been made in improving these devices for use in practical applications. The power consumption and reliability of OLEDs have been key issues for real applications, and remarkable progress has been made through intensive research in the past decade. ${ }^{3-5}$ Functional devices based on conjugated polymers or small molecules such as light emitting diodes (OLEDs), organic solar cells (OSCs) and organic field-effect transistors (OFETs) have great potential for light weight, flexible and low-cost electronic and optoelectronic applications. ${ }^{6}$ To obtain highly efficient and low-voltage OLEDs, the optimization of charge injection and carrier transport is critically important towards the improvement of device performances. ${ }^{7,8}$ The doping of organic semiconductors was first studied in the year $1960,{ }^{9}$ however they have been extensively studied after their use in enhancing the charge carrier injection and transport properties in optoelectronic devices, ${ }^{\mathbf{1 0 - 1 5}}$ such as OLEDs and OSCs. Despite the extensive studies on p-type and n-type doping of organic semiconductors, doping optimization in organic semiconductors still remains a challenge.

CSIR-Network of Institutes for Solar Energy, Physics of Energy Harvesting division, CSIR-National Physical Laboratory, New Delhi, India. E-mail: cksuman@gmail.com
In all of these organic devices, the optimization of the charge injection/extraction and carrier transport is critically important towards their technological success. ${ }^{16-18}$ Efficient injection or extraction requires low energetic barriers, while competent transport demands highly conductive transport layers. Organic semiconductors have low carrier concentrations and low carrier mobilities. ${ }^{18,19}$ A widely used method for improving electron injection and transport is to employ lowwork-function metals, either as individual layers in contact with the cathode or as n-type conductive dopants in the organic electron-injection layers (EILs), which can help to reduce the injection barrier at the electrode/organic interface and provide excellent electron injection from the cathode to the organic layer. ${ }^{\mathbf{2 0 - 2 4}}$ Alkali metals such as Li, Cs and their oxides have also been used for n-type conductive doping of organic electron transport materials ${ }^{25-27}$ and were found to be useful in many instances. However, this type of doping has lots of problems, including damage to the underlying organic layers due to the tendency to diffuse in the organic materials. For this reason, there is a need for molecular dopants to enhance the electron transporting properties and for use in OLED applications.

Here, we have compared the use of TiOPc as an n-type dopant of $\mathrm{Alq}_{3}$ at different concentrations. The thin films of doped and undoped materials were studied and investigated for their application in lighting devices (OLEDs). 


\section{Experimental methods}

The electron only devices were fabricated with the structure $\mathrm{Al}\left|\mathrm{Alq}_{3}: \mathrm{TiOPc}\right| \mathrm{Al}$. The $\mathrm{Alq}_{3}$ was doped with TiOPc with weight percentage doping concentrations of 1,2, 3 and $5 \%$; those thin films and devices were named as $\mathrm{Alq}_{3}: \mathrm{T} 1, \mathrm{Alq}_{3}: \mathrm{T} 2, \mathrm{Alq}_{3}: \mathrm{T} 3$ and $\mathrm{Alq}_{3}: \mathrm{T} 5$, respectively. The doping of the organic layers was performed by a thermal co-evaporation process. Similarly, light emitting diodes (OLEDs) were fabricated on indium-tin-oxide (ITO) (purchased from Vin Karola USA) coated glass substrates with a sheet resistance of $20 \Omega \mathrm{sq}^{-1}$. Before depositing all organic materials, the ITO substrates were cleaned ultrasonically with de-ionized water, acetone and isopropyl alcohol, and finally dried. The deposition rate was kept at $1-2 \AA \mathrm{s}^{-1}$ for the organic layers and $2-5 \AA \mathrm{s}^{-1}$ for the aluminum as the metal cathode. The overlap of the ITO anode and the Al cathode defines the active area of the device to be $6 \mathrm{~mm}^{2}$.

The current density-voltage $(J-V)$, current density-voltageluminescence $(J-V-L)$ and current efficiency-current densitypower efficiency characteristics of the OLEDs were measured simultaneously with a programmable Keithley 2400 power source and a Luminance meter (LMT-1009). Impedance spectroscopy (IS) measurements were performed using an Impedance/Gain-Phase Analyzer (Solartron, model SI 1260) Characterization System. A $100 \mathrm{mV}$ amplitude AC signal superimposed on a DC bias was used to measure the device impedance as a function of the AC frequency and DC bias.

\section{Results and discussion}

The surface morphologies of the doped and undoped $\mathrm{Alq}_{3}$ thin films were characterized by atomic force microscopy (AFM). Fig. 1(A)-(E) show the AFM images of $\mathrm{Alq}_{3}, \mathrm{Alq}_{3}: \mathrm{T} 1, \mathrm{Alq}_{3}: \mathrm{T} 2$, $\mathrm{Alq}_{3}: \mathrm{T} 3$ and $\mathrm{Alq}_{3}: \mathrm{T} 5$. The surface roughness increases with increasing the concentration of TiOPc. The RMS values of roughness are $0.3914 \mathrm{~nm}, 0.5549 \mathrm{~nm}, 0.5742 \mathrm{~nm}, 0.6146 \mathrm{~nm}$ and $6.2326 \mathrm{~nm}$ for $\mathrm{Alq}_{3}, \mathrm{Alq}_{3}: \mathrm{T}_{1}, \mathrm{Alq}_{3}: \mathrm{T}_{2}, \mathrm{Alq}_{3}: \mathrm{T} 3$ and $\mathrm{Alq}_{3}: \mathrm{T} 5$ respectively. The thin films of $\mathrm{Alq}_{3}, \mathrm{Alq}_{3}: \mathrm{T} 1$ and $\mathrm{Alq}_{3}: \mathrm{T} 2$ consist of small uniform 3D islands with a compact shape. The surface morphology changes drastically if the doping concentration is increased above $2 \%$ : an island shape transition occurs resulting in typical needle-like structures with elongated 3D-islands. Fig. 1(E) shows that the islands become thereby progressively longer, quickly reaching a fixed asymptotic width while their height remains much longer than their width. Hence high doping concentrations of TiOPc are not suitable for device application.

Since the Al work function is about $4.2 \mathrm{eV}$ and the $\mathrm{Alq}_{3} \mathrm{LUMO}$ value is $3.0 \mathrm{eV},{ }^{28}$ the electron injection barrier between $\mathrm{Al}$ and $\mathrm{Alq}_{3}$ will be very high. However, in between the $\mathrm{Al}$ and $\mathrm{Alq}_{3}$ films it is observed that there are large interface dipoles present, ${ }^{29}$ which reduces the electron injection barrier by about $1.0 \mathrm{eV}$, hence the net barrier present is $0.2 \mathrm{eV}$. In the same way, the energy barrier for hole injection is increased by $1.0 \mathrm{eV}$ due to the interface dipole and the resultant barrier for hole injection becomes $2.5 \mathrm{eV}$. Therefore, holes are not injected compared to the injection of electrons, and any current observed in the
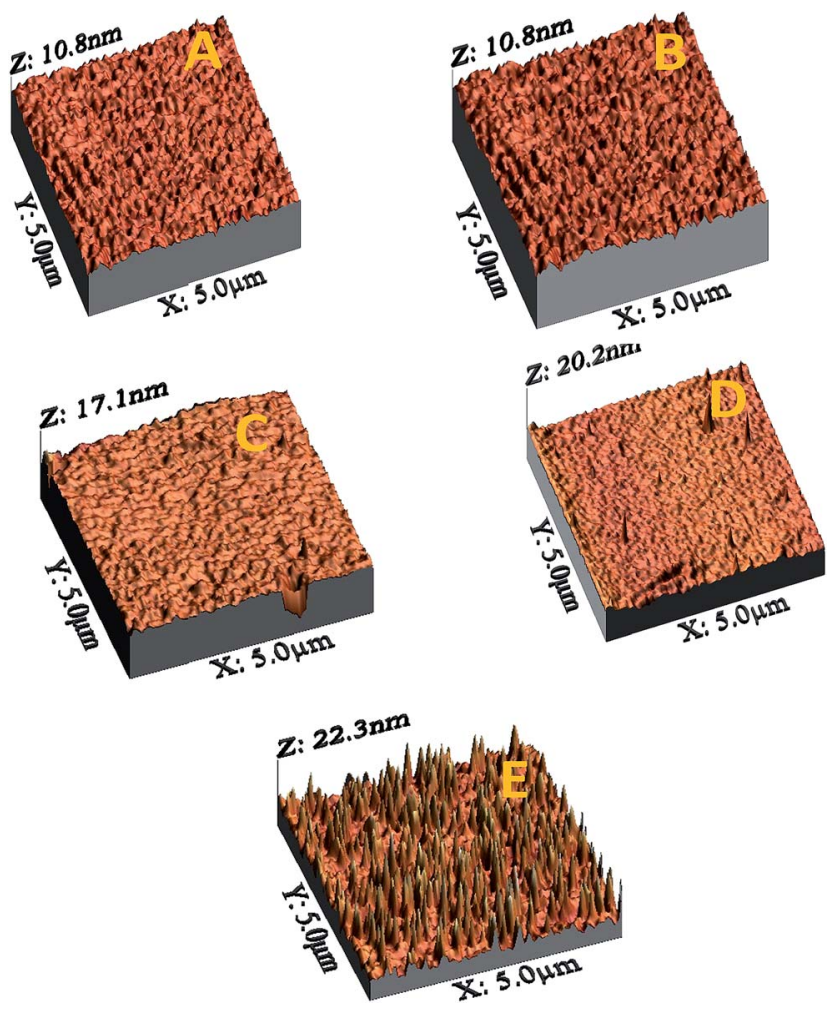

Fig. 1 The AFM images $(5 \mu \mathrm{m} \times 5 \mu \mathrm{m})$ of TiOPc doped Alq $q_{3}$ thin films; (A) $A l q_{3},(B) A l q_{3}: T 1$, (C) Alq $: T 2$, (D) Alq $: T 3$ and (E) Alq $3: T 5$.

device will be only due to electrons flowing between the two $\mathrm{Al}$ electrodes. Therefore, the electron only devices can be considered to have the structure of $\mathrm{Al} /$ organic/Al. The thicknesses of the organic films were kept at $100 \mathrm{~nm}$ for all of the five devices. Fig. 2 shows the $J-V$ characteristics of the electron only $\mathrm{Alq}_{3}$, $\mathrm{Alq}_{3}: \mathrm{T} 1, \mathrm{Alq}_{3}: \mathrm{T} 2, \mathrm{Alq}_{3}: \mathrm{T} 3$ and $\mathrm{Alq}_{3}: \mathrm{T} 5$ devices. The inset of Fig. 2 shows an enlarged $J-V$ plot with a logarithmic $x$ axis. It is clearly shown in the inset figure that the driving voltage of the electron

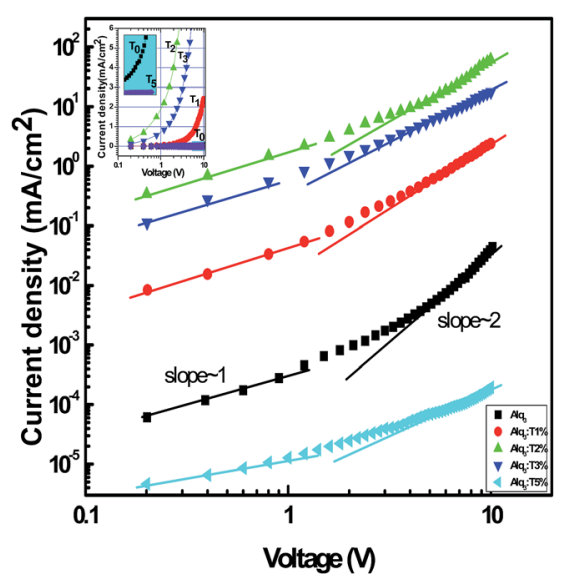

Fig. 2 The current density-voltage $(J-V)$ characteristics of the electron only devices of the Alq $3:$ TiOPc thin films. The structure of the device was Al/Alq $3: T(1-5 \%) / A l$. Inset: an enlarged view of the $J-V$ characteristics with a logarithmic $x$ axis. 
only devices shifts with the doping concentration. The current density increases linearly with the increase of voltage in the lower voltage region, and in the high voltage region the current density increases non-linearly for all of the devices. At low voltages (the first region of the $J-V$ curve), the slope of the $\log J-V$ plots are approximately unity, while at higher voltages, the slope is about 2 or more. Hence the conductivity is clearly Ohmic at low voltage and exhibits space charge limited conductivity (SCLC) at higher voltages. In the Ohmic region of the conductivity, the current density can be expressed as $J=q n_{0} \mu \frac{v}{d}$, where $n_{0}$ is the concentration of thermally activated carriers, $\mu$ is the mobility and $d$ is the thickness of the organic semiconductor used $(d=100 \mathrm{~nm})$. In the high voltage region (the second region of the $J-V$ curve) $J \propto V^{2}$ indicating a limited current controlled by a space charge with a single discrete set of shallow traps. The current density in this region is $J=\frac{9}{8} \varepsilon \mu \theta \frac{v^{2}}{d^{3}}$, where $\varepsilon$ is the organic semiconductor dielectric constant (taken as 3.5), $\mu$ is the charge carrier mobility and $\theta$ is the trapping fraction. The trapping fraction can be represented by $\theta=\frac{n_{0}}{n_{0}+n_{\mathrm{t}}}$, where $n_{0}$ is the free charge carrier density and $n_{\mathrm{t}}$ is the trapped charge carrier density. The electron mobility of $\mathrm{Alq}_{3}$, calculated assuming trap free SCLC $\left(n_{\mathrm{t}}=0\right)$, was $0.62 \times 10^{-8} \mathrm{~cm}^{2} \mathrm{~V}^{-1} \mathrm{~s}^{-1}$ which is comparable to the mobility obtained from the TOF technique. ${ }^{30}$ The mobilities for the doped thin films are $0.7 \times$ $10^{-7}, 0.17 \times 10^{-5}, 0.75 \times 10^{-6}$ and $0.68 \times 10^{-9} \mathrm{~cm}^{2} \mathrm{~V}^{-1} \mathrm{~s}^{-1}$ for $\mathrm{Alq}_{3}: \mathrm{T} 1, \mathrm{Alq}_{3}: \mathrm{T} 2, \mathrm{Alq}_{3}: \mathrm{T} 3$ and $\mathrm{Alq}_{3}: \mathrm{T} 5$, respectively. The mobility for the $\mathrm{Alq}_{3}: \mathrm{T} 2$ thin film is higher than all of the four other dopant concentrations in the thin films. The electron mobility of the $\mathrm{Alq}_{3}$ :T2 thin film is four orders of magnitude greater than that of the $\mathrm{Alq}_{3}$ device. The suitable doping concentration provides new hopping sites for the carrier that leads to an increased mobility in the organic semiconductor. The other reasons for the enhanced electron mobility may be the broadening of the density of states and charge transfer. ${ }^{31}$ Doping $\mathrm{Alq}_{3}$ with common inorganic insulators (Li salts) creates radical ions of $\mathrm{Alq}_{3}$ which are responsible for the $\mathrm{n}$ type doping effect. Similar negative charge enriched thin films are achieved by organic molecular doping. ${ }^{32}$

Fig. 3 shows (A) the energy level diagram of the OLED and (B) the electroluminescence spectra of the device at different bias voltages. The inset of Fig. 3(B) shows photographs of the light output at bias voltages of $8 \mathrm{~V}$ and $15 \mathrm{~V}$. The fabricated OLED structure consists of $35 \mathrm{~nm} N, N^{\prime}$-di(naphthalene-1-yl)- $N, N^{\prime}$ diphenylbenzidine (NPB) as a hole-transporting layer (HTL), 35 $\mathrm{nm}$ tris(2-phenylpyridine)iridium(III) $\left[\operatorname{Ir}(\mathrm{ppy})_{3}\right]$ (5\%) doped in a 4,4'-bis-(carbazol-9-yl)-biphenyl (CBP) green light emitting layer (EML), a 6 nm-thick 2,9-dimethyl-4,7-diphenyl-1,10-phenanthroline (BCP) hole-blocking layer (HBL) and a $28 \mathrm{~nm}$ thick titanyl phthalocyanine (TiOPc) doped tris(8-hydroxyquinolinato) aluminum $\left(\mathrm{Alq}_{3}\right)$ electron transport layer (ETL). The doping of $\operatorname{Ir}(\mathrm{ppy})_{3}$ into the CBP facilitated the control of triplet quenching at the interfaces. ITO and lithium fluoride (LiF) $(1 \mathrm{~nm}) /$ aluminium $(\mathrm{Al})(100 \mathrm{~nm})$ were used for the anode and cathode, respectively. The device structure of the green

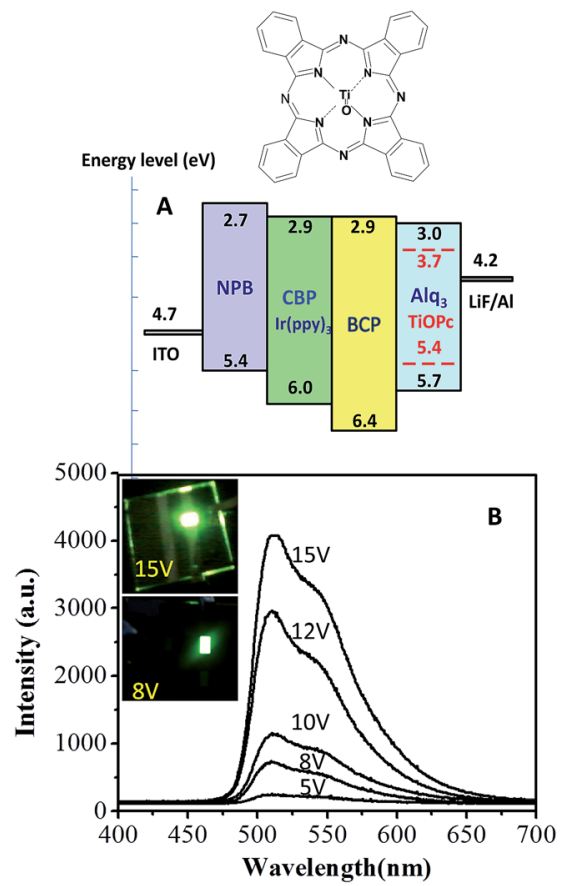

Fig. 3 (A) The molecular structure of TiOPc and an energy level diagram for the OLEDs. (B) The electroluminescence spectra of the OLEDs at different bias voltages; the inset shows photographs of the light output at $8 \mathrm{~V}$ and $15 \mathrm{~V}$ bias voltages.

phosphorescent OLEDs is $\left[\mathrm{ITO} / \mathrm{NPB} / \mathrm{CBP}: \operatorname{Ir}(\mathrm{ppy})_{3} / \mathrm{BCP} /\right.$ $\left.\mathrm{Alq}_{3}: \mathrm{T}(x) / \mathrm{LiF} / \mathrm{Al}\right]$. The EL spectra showed an emission only from $\operatorname{Ir}(\mathrm{ppy})_{3}$ with no emission from the neighboring materials. The emission pattern is in the green spectral range of the visible regime, with its main peaks at $515 \mathrm{~nm}$ and an additional shoulder at $550 \mathrm{~nm}$. There is no significant shift in the position of the emission peaks within the applied bias range. The emission color is stable in the investigated bias voltage region.

Fig. 4 shows the $J-V-L$ characteristics of the OLEDs containing $\mathrm{Alq}_{3}, \mathrm{Alq}_{3}: \mathrm{T} 1, \mathrm{Alq}_{3}: \mathrm{T} 2, \mathrm{Alq}_{3}: \mathrm{T} 3$ and $\mathrm{Alq}_{3}: \mathrm{T} 5$ as the ETLs,

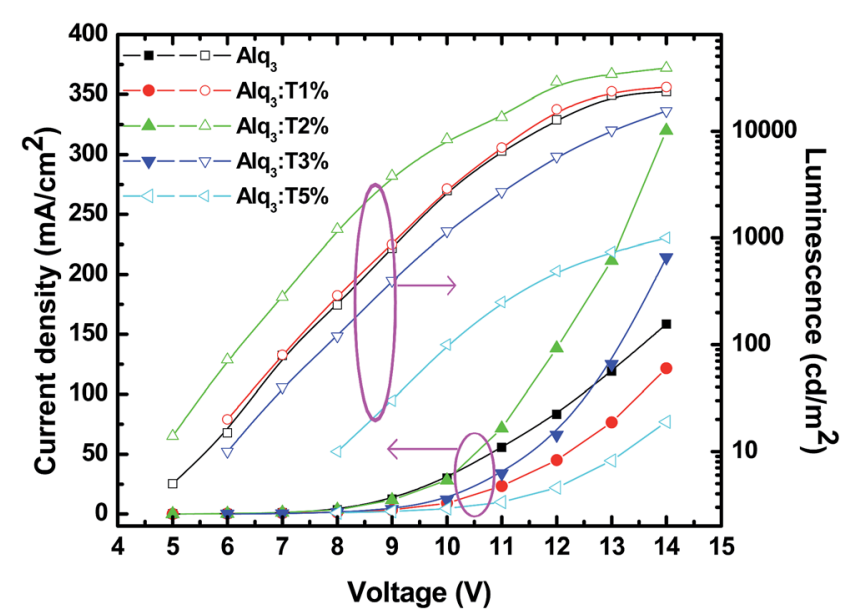

Fig. 4 The current density-voltage-luminescence $(J-V-L)$ characteristics of devices with different doping quantities of TiOPc with $\mathrm{Alq}_{3}$. 
respectively. The current density at high voltage increases with the TiOPc doping concentration up to $2 \%$. Above $2 \%$ doping the value of the current density is found to be low in comparison to undoped ETL. At a fixed bias of $11 \mathrm{~V}$, the current density of the devices containing $\mathrm{Alq}_{3}, \mathrm{Alq}_{3}: \mathrm{T} 1, \mathrm{Alq}_{3}: \mathrm{T} 2, \mathrm{Alq}_{3}: \mathrm{T} 3$ and $\mathrm{Alq}_{3}: \mathrm{T} 5$ are $57.81,24.35,72.35,47.62$ and $11.26 \mathrm{~mA} \mathrm{~cm}^{-2}$, respectively. The current density of the $\mathrm{Alq}_{3}: \mathrm{T} 2$ OLED increased by $25 \%$ compared to the pristine $\mathrm{Alq}_{3}$ device. The driving voltage is reduced for the $\mathrm{T} 2$ device, which indicates the enhancement of the electron injection and transport by suitable ETLs. The luminescences of the devices based on $\mathrm{Alq}_{3}$ to $\mathrm{Alq}_{3}: \mathrm{T} 5$ at a current density of $10 \mathrm{~mA} \mathrm{~cm}{ }^{-2}$ are 3098, 4700, 7800, 3600 and $520 \mathrm{~cd} \mathrm{~m}^{-2}$, respectively. At this value of current density, the luminescence is doubled. This enhancement in electroluminescence may be attributed to the enhancement of the holes and electrons recombination rate.

Fig. 5(a) and (b) show the current efficiency and power efficiency as a function of current density for the $\mathrm{Alq}_{3}$ to $\mathrm{Alq}_{3}: \mathrm{T} 5$ devices, respectively. It can be clearly observed in Fig. 5(a) and (b) that the trend in the efficiencies is consistent with the variation of the electrical properties of the devices with the use of different ETLs, and the improved electrical properties lead to the enhanced device efficiency. These results indicate that the TiOPc doping provides a balance of carriers. The control of both carriers in the device gives high yield electroluminescence. At a $35.19 \mathrm{~mA} \mathrm{~cm}^{-2}$ current density, the current efficiency of $\mathrm{Alq}_{3}: \mathrm{T} 2$ is five times that of the $\mathrm{Alq}_{3}$ devices. At a current density of 10 $\mathrm{mA} \mathrm{cm}{ }^{-2}$, the power efficiency of the $\mathrm{Alq}_{3}: \mathrm{T} 2$ device doubled compared to the pristine $\mathrm{Alq}_{3}$ device. The overall current efficiency and power efficiency was increased for the $2 \%$ doped devices.

The capacitance-voltage $(C-V)$ studies provide information on the electronic properties of the OLEDs. The $C-V$ characteristics were measured at a fixed frequency of $1000 \mathrm{~Hz}$ under dark conditions as shown in Fig. 6. At negative to positive bias $(-2$ to $4 \mathrm{~V})$, a constant capacitance was observed that corresponds to the geometrical capacitance of the device. The capacitances of all of the devices start increasing with the increase of bias voltage (above $4 \mathrm{~V}$ ) and after reaching maximum values, they start to decrease for further increases of bias

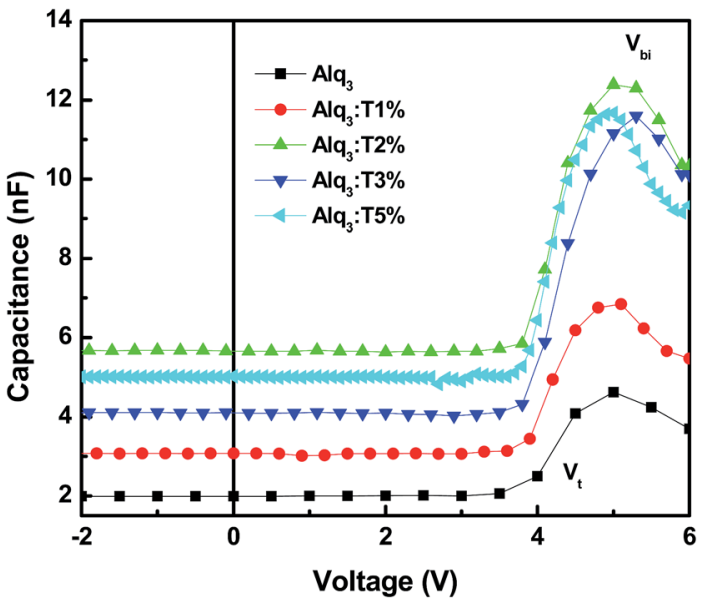

Fig. 6 Capacitance-voltage $(C-V)$ characteristics of the OLEDs at a frequency of $1000 \mathrm{~Hz}$.

voltage. The increase of capacitance may be due to the accumulation of charge at the $\mathrm{Alq}_{3}$ :TiOPc interface. As the electrons and holes recombined, the charge is annihilated, thus the capacitance decreases rapidly with the increasing of applied bias. Since, $V_{\mathrm{t}} \neq V_{\mathrm{bi}}$ it simply means that a negative interfacial charge density $\sigma_{\text {if }}$ is present. Its value can be calculated from the following equation: ${ }^{33,34}$

$$
\sigma_{\text {if }}=Q_{\text {if }} / \mathrm{A}=\frac{\varepsilon_{0} \varepsilon_{\mathrm{r}}}{d_{\mathrm{Alq}_{3}: \mathrm{T}}}\left(V_{\mathrm{t}}-V_{\mathrm{bi}}\right)
$$

with $\varepsilon_{\mathrm{r}} \approx 3, A=6 \mathrm{~mm}^{2}$ and $d_{\mathrm{Alq}_{3}}=30 \mathrm{~nm}$. The $Q_{\text {if }}$ and $\sigma_{\text {if }}$ for all of the studied devices $\mathrm{Alq}_{3}$ to $\mathrm{Alq}_{3}$ :T5 are $-2.95,-2.9,-4.6,-4.2$, and $-2.5 \mathrm{nC}$ and $-0.49,-0.48,-0.77,-0.7$ and $-0.42 \mathrm{mC} \mathrm{m}^{-2}$, respectively. In the case of no interfacial charge the threshold voltage and the built-in voltage would be equal $\left(V_{\mathrm{t}}=V_{\mathrm{bi}}\right)$, as the flat-band case would be reached simultaneously in the TiOPc and the $\mathrm{Alq}_{3}$ layer.

The Cole-Cole plots of all of the devices at a $0 \mathrm{~V}$ bias and room temperature are shown in Fig. 7. The equivalent circuit of these devices consists of a parallel resistance $\left(R_{\mathrm{P}}\right)$ and capacitance $\left(C_{\mathrm{P}}\right)$ network in series with the contact resistance $\left(R_{\mathrm{S}}\right)$. The
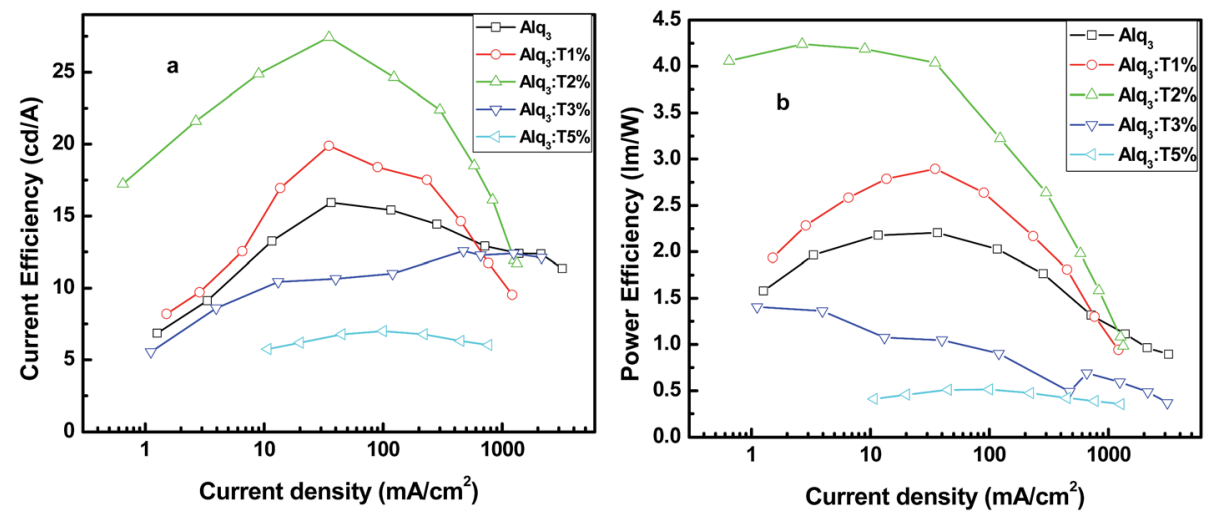

Fig. 5 (a) Current efficiency vs. current density characteristics of the $A_{l} q_{3}$ and $A l q_{3}: T(1,2,3 \& 5 \%)$ devices; (b) power efficiency-current density characteristics of the $\mathrm{Alq}_{3}$ and $\mathrm{Alq}_{3}: \mathrm{T}(1,2,3$ \& 5\%) devices. 


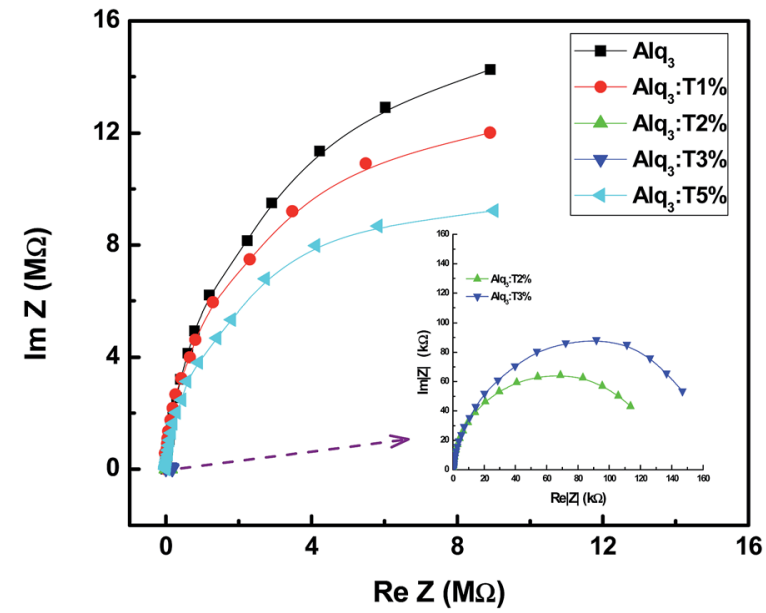

Fig. 7 Cole-Cole plot of the $\mathrm{Alq}_{3}$ and $\mathrm{Alq}_{3}: \mathrm{T}(1,2,3$ \&5\%) OLEDs at a $0 \mathrm{~V}$ bias. The inset shows an enlarged curve for the Alq $3: \mathrm{T2}$ and $\mathrm{Alq}_{3}: \mathrm{T3}$ devices.

$R_{\mathrm{S}}$ circuit element that corresponds to the intersection of the semicircle at high frequencies represents resistive losses at the ITO and $\mathrm{Al}$ electrodes. In this work, we have shown the equivalent $R-C$ electrical circuit for a three layered structure of a device in which NPB is the hole transporting layer, CBP:Ir(ppy) is the emissive layer and $\mathrm{Alq}_{3}: \mathrm{T}$ is the electron transport layer, which consists of three parallel $R-C$ circuits connected in series with contact resistance $\left(R_{\mathrm{S}} \sim 0 \Omega\right)$ as shown in the inset of Fig. 7 . From Fig. 7, it is observed that the diameter of the semicircle is highly dependent on the resistance of the devices, which represents the bulk resistance of the organic layers $R_{\mathrm{b} 1}$ to $R_{\mathrm{b} 3}$. The decrease in the diameter of the semicircle is in response to the increase of the resistance of the TiOPc doped $\mathrm{Alq}_{3}$ layer which is also reflected in the $J-V$ characteristics (Fig. 4). The equivalent resistance for devices $\mathrm{Alq}_{3}$ to $\mathrm{Alq}_{3}: \mathrm{T} 5$ are $10 \mathrm{M} \Omega$, $8 \mathrm{M} \Omega, 70 \mathrm{k} \Omega, 90 \mathrm{k} \Omega$ and $6 \mathrm{M} \Omega$, respectively.

\section{Conclusion}

In conclusion, the doping of TiOPc into $\mathrm{Alq}_{3}$ contributes to an increase of the electron mobility in the $\mathrm{Alq}_{3}$, and as a result the performance of the related OLEDs are enhanced. The increase in mobility is attributed to the addition of new hopping sites for carriers after doping. The surface roughness increases with doping concentrations, and the optimized roughness is found to be $0.5742 \mathrm{~nm}$ for $2 \%$ doping. The electron transport is well described by space-charge limited current in the doped and pristine studied thin films of $\mathrm{Alq}_{3}$. The electron mobility of the $2 \%$ doped thin films is $0.17 \times 10^{-5} \mathrm{~cm}^{2} \mathrm{~V}^{-1} \mathrm{~s}^{-1}$ which is three orders of magnitude greater than that of the $\mathrm{Alq}_{3}$ film. The electroluminescence $\left(\sim 7800 \mathrm{~cd} \mathrm{~m}^{-2}\right)$ at a current density of 10 $\mathrm{mA} \mathrm{cm}{ }^{-2}$ is 2.6 times higher than that of the undoped device. The interfacial charge density for the $2 \%$ doped OLED device is $-0.77 \mathrm{mC} \mathrm{m}^{-2}$. The Cole-Cole plot of the OLEDs can be modeled as the combination of three parallel resistancecapacitance $(R-C)$ equivalent circuits with a series resistance $\left(R_{\mathrm{S}} \sim 0 \Omega\right)$. The equivalent resistance of the optimized device
(2\% doping) is $70 \mathrm{k} \Omega$ whereas the resistances of the other devices are in the mega-ohm range.

\section{Acknowledgements}

The authors gratefully recognize the financial support from the Council of Scientific and Industrial Research (CSIR), India for funding our research work.

\section{References}

1 C. W. Tang and V. Slyke, Appl. Phys. Lett., 1987, 51, 913.

2 C. W. Tang, V. Slyke and C. H. Chen, J. Appl. Phys., 1989, 65, 3610.

3 M. A. Baldo, D. F. O' Brien, Y. You, et al., Nature, 1998, 395, 151.

4 V. E. Choong, S. Shi, J. Curless, et al., Appl. Phys. Lett., 1999, $75,172$.

5 S. A. V. Slyke, C. H. Chen and C. W. Tang, Appl. Phys. Lett., 1996, 69, 2160.

6 R. Steyrleuthner, S. Bange and D. Nehar, J. Appl. Phys., 2009, 105, 064509.

7 L. S. Hung, C. W. Tang and M. G. Mason, Appl. Phys. Lett., 1997, 70, 152.

8 Z. Xu, L. M. Chen, G. Yang, C. H. Huang, J. Hou, Y. Wu, G. Li, C. S. Hsu and Y. Yang, Adv. Funct. Mater., 2009, 19, 1227.

9 M. Pope and C. E. Swenberg, Electronic Process in Organic Crystals and Polymers, Oxford University Press, Oxford, U.K, 1999.

10 M. Pfeiffer, A. Beyer, T. Fritz and K. Leo, Appl. Phys. Lett., 1998, 73, 729.

11 M. Pfeiffer, A. Beyer, T. Fritz and K. Leo, Appl. Phys. Lett., 1998, 73, 3202.

12 M. Pfeiffer, T. Fritz, J. Blochwitz, A. Nollau, B. Plonnigs, A. Beyer and K. Leo, Adv. Solid State Phys., 1999, 39, 77.

13 C. Ganzorig and M. Fujihira, Appl. Phys. Lett., 2000, 77, 4211.

14 X. Zhou, M. Pfeiffer, J. Blochwitz, A. Werner, A. Nollau, T. Fritz and K. Leo, Appl. Phys. Lett., 2001, 78, 410.

15 A. Kumar, R. Srivastava, P. Tyagi and D. S. Mehta, J. Appl. Phys. Lett., 2011, 109, 114511.

16 K. R. Choudhury, J. H. Yoon and F. So, Adv. Mater., 2008, 20, 1456.

17 Y. Shirota and H. Kageyama, Chem. Rev., 2007, 107, 953.

18 V. Coropceanu, J. Comil, D. A. S. Filho, Y. Oliver, Y. Silve and J. L. Bredas, Chem. Rev., 2007, 107, 926.

19 W. Brutting, S. Berleb and A. G. Muckl, Org. Electron., 2001, 2, 1.

20 K. Walzer, B. Maening, M. M. Pfeiffer and K. Leo, Chem. Rev., 2007, 107, 1233.

21 W. Ou-yang, M. Weis, X. Chen, T. Manaka and M. Iwamoto,J. Chem. Phys., 2009, 131, 104702.

22 Y. Zhou, C. Fuentes-Hernandez, J. Shim, J. Meyer, A. J. Giodano, H. Li, P. Winget, T. Papadopoulos, H. Cheun, J. Kim, M. Fenoll, A. Dindar, W. Haske, E. Najafabadi, T. M. Khan, H. Sojoudi, S. Barlow, S. Graham, J. L. Bredas, S. R. Marder, A. Khan and B. Kippelen, Science, 2012, 336, 327. 
23 D. Taguchi, T. Shino, X. Chen, L. Zhang, J. Li, M. Weis, T. Manaka and M. iwamoto, J. Appl. Phys., 2011, 110, 103717.

24 Y. H. Deng, Y. Q. Li, Q. D. Ou, Q. K. Wang, F. Z. Sun, X. Y. Chen and J. X. Tang, Org. Electron., 2014, 15, 1215.

25 J. Kido, K. Nagai and Y. Okamoto, IEEE Trans. Electron Devices, 1993, 40, 1342.

26 J. Kido and T. Matsumoto, Appl. Phys. Lett., 1998, 73, 2866.

27 A. Werner, F. Li, K. Harada, M. Pfeiffer, T. Fritz, K. Leo and S. Machill, Adv. Funct. Mater., 2004, 14, 255.

28 R. Q. Zhang, C. S. Lee and S. T. Lee, J. Chem. Phys., 2000, 112, 8614.
29 H. Ishii, K. Sugiyama, E. Ito and K. Seki, Adv. Mater., 1999, 11, 605.

30 G. G. Malliaras, Y. Sen, D. H. Dunlup, H. Murata and Z. H. Kafafi, Appl. Phys. Lett., 2001, 79, 2582.

31 O. Tal, Y. Rosenwaks, Y. Preezant, N. Tessler, C. K. Chan III and A. Kahn, Phys. Rev. Lett., 2005, 95, 256405.

32 P.-C. Kao, J.-H. Lin, J.-Y. Wang, C.-H. Yang and S.-H. Chen, J. Appl. Phys., 2011, 109, 094505.

33 W. Brutting, S. Berleb and A. G. Muckl, Org. Electron., 2001, $2,1$.

34 S. Nowy, W. Ren, J. Wagner, J. A. Weber and W. Brutting, Proc. SPIE, 2009, 7415, 74150G-1. 